\title{
Mortality and Survival Probability of Female Pigs in Southern European Commercial Breeding Herds
}

\author{
Satomi Tani ${ }^{1}$, Carlos Piñeiro ${ }^{2} \&$ Yuzo Koketsu ${ }^{1}$ \\ ${ }^{1}$ School of Agriculture, Meiji University, Kawasaki, Japan \\ ${ }^{2}$ PigCHAMP Pro Europa, Segovia, Spain \\ Correspondence: Satomi Tani, School of Agriculture, Meiji University, Higashi-mita 1-1-1, Tama-ku, Kawasaki, \\ Kanagawa 214-8571, Japan. Tel: 81-44-934-7826. E-mail: composition.013@gmail.com
}

\author{
Received: January 9, $2017 \quad$ Accepted: February 15, $2017 \quad$ Online Published: March 15, 2017 \\ doi:10.5539/jas.v9n4p38 URL: https://doi.org/10.5539/jas.v9n4p38
}

The research is financed by Research Project Grants (Giken A 2012-2016) and Graduate School GP 2016 from Meiji University.

\begin{abstract}
This retrospective cohort study characterized death occurrences in female pigs in commercial herds, examined the survival probability for served females, and quantified factors associated with by-parity mortality risks for farrowed sows. The cohort data from herd entry to removal included 558,486 first service records of 113,517 females in 121 herds, served between 2008 and 2013. Two herd categories were defined on the basis of the lower 25th percentiles of herd means of annualized lifetime pigs weaned per sow: low-performing herds and ordinary herds. Two-level survival analysis was performed for served females to obtain by-parity survival probabilities (gilts and parity 1-6 sows). Also, log-binomial regression models were used to examine risk factors and ratios associated with mortality risks for the seven parity groups farrowed in either spring, summer, autumn or winter. Overall mean mortality incidence rates were 1.22 and 5.30 pigs per 100 pig-days of observation for pregnant females and farrowed sows, respectively. Survival probabilities for served females rapidly decreased by $2.3 \%-3.7 \%$ around farrowing in all parity groups. The lower survival probabilities were associated with increased age at first-mating, females in low-performing herds, sows farrowing more stillborn piglets and sows having weaning-to-first-mating interval of 7 days or more $(\mathrm{P}<0.05)$. Mortality risks were assessed for herds, served month, WMI and stillborm piglets. Increased risks were associated with summer farrowing, low-performing herds and more stillborn piglets $(\mathrm{P}<0.05)$. We recommended that producers individually monitor high risk female groups, and provide prompt treatment to any females with problems.
\end{abstract}

Keywords: death interval, mortality risk, mortality incidence rate, relative risk, swine

\section{Introduction}

Decreasing the mortality risk in female breeding-pigs is critical to enhance maternal health and animal welfare in commercial herds, and it also helps prevent decreased productivity, economic losses and reduced worker morale. A recent report showed that the annual death rate in breeding herds in the U.S.A. is 8.9\% (PigCHAMP, 2015). Also, another U.S. study showed that the mortality risk rose as the number of parity increased from 0 to 7 or higher (Koketsu, 2000). In addition, both peripartum periods and farrowing events have been reported as major risk factors for sow mortality (Sasaki \& Koketsu, 2008). However, mortality incidence rates in pregnant pigs and farrowed sows have not been well widely measured in relation to pig days. In the few studies have looked at these issues, one recent study indicated that risk factors such as summer months or high outside temperature, and high parity number are associated with higher mortality risks for sows around farrowing (Iida \& Koketsu, 2014). Another study found that a higher abortion risk was associated with an increased number of stillborn piglets (Iida \& Koketsu, 2015). Also, it was foud that lower herd productivity, measured as pigs weaned per sow per year, was associated with higher mortality risks for sows in parities 4 and 5 or higher (Sasaki \& Koketsu, 2008). However, no studies have examined and quantified any other possible factors, such as the number of stillborn piglets and being fed in low-performing herds. 
Southern Europe is a major pig producing region. Spain and Portugal have $21.4 \%$ of all female pigs in the $28 \mathrm{EU}$ countries, with 2,568,450 female pigs in 19,630 breeding herds in Spain and 186,960 female pigs in 7,910 herds in Portugal in 2013 (European Commission, 2016). However, few studies have characterized death intervals in commercial herds in this region.

With regard to suitable analysis methods for such mortality risk studies, it has been recommended that log-binomial regression models with risk ratios would be better in cohort studies, rather than logistic regression models with odds ratios (Spiegelman \& Hertzmark, 2005). However, log-binomial regression models have not been used to examine the risk ratios in southern European commercial breeding herds. Nor has two-level survival analysis, that would take account of the hierarchical structure of the individual females within a herd (Singer, 1998), been applied to death occurrences from service to subsequent service in commercial herds. Therefore, the objectives of the present study were to characterize death occurrences in female pigs in southern European commercial herds, to examine multi-level survival probability for served females, and to quantify factors associated with by-parity mortality risk and risk ratios for farrowed sows.

\section{Method}

\subsection{Study Herds}

A consultancy firm (PigCHAMP Pro Europa S.L. Segovia, Spain) has requested all client producers to mail their data files on a regular basis in order to create a research database. At the end of 2013, 121 of the 150 client herds in Spain and Portugal (81\%) allowed their herd data to be used for research purposes. Data were collected from 98 Spanish and 23 Portuguese herds. Mean $( \pm$ SEM) average herd size was $679 \pm 53.0$ females $(699 \pm 64.3$ : Spain; $592 \pm 50.3$ : Portugal) with a range between 81 and 3,222 females. Herd size data was collected from the first month up to the final month of the collected data in June 2013. The study herds increased in size by $14.2 \%$ over the 3 years of collected data.

Data about whether individual herds used natural or mechanical ventilation systems in their farrowing, breeding and gestation barns was not available in this study. Diets for gestation and lactation are formulated using cereals (barley, wheat and corn) and soybean meal. Also, all the herds use artificial insemination with double or triple inseminations of sows during an estrous period. Replacement gilts for the 121 herds are either purchased from breeding companies or are home-produced through their internal multiplication programs. The herd data used in the present study is a subset data from a previous study about recurrence patterns of returns (Tani et al., 2016).

\subsection{Study Design, Data Collection and Exclusion Criteria}

The present study was designed as a retrospective cohort study coordinating by-parity service records from herd entry to removal for female pigs entered into the herds from 2008 to 2010 using the PigCHAMP recording system at the end of 2013. Service records were collected from January 2008 to June 2013, because the female pigs lived up to 3 years. When the data were collected, 5,103 (4.3\%) of the 118,620 sows had not yet been removed, and so they were excluded. Additionally, re-service records (61,104 re-service records) of the 619,590 service records were not used in the study. Thus, the initial data contained 558,486 first-served records and 113,517 lifetime records in the 121 herds.

Three datasets were created: Dataset 1 for death intervals in lifetime records, Dataset 2 for calculating mortality incidence rates and survival analysis, and Dataset 3 for log-binomial regression models. Records were excluded from Dataset 1 if they met any of the following criteria: last gestation length of 123 days or more (447 females), and sows that farrowed and were subsequently removed 11 or more weeks after farrowing (426 sows). Hence, Dataset 1 comprised lifetime records of 16,396 dead females. In Dataset 2, service records were omitted as missing records if they met any of the following criteria: total number of pigs born was 0 pigs or 26 pigs or more (817 records; Lundgren et al., 2010); lactation length was greater than 41 days (1,966 records: Tummaruk et al., 2001) and weaning-to-first-mating interval [WMI] was 36 days or more (4,475 records; Hoving et al., 2011). Also, when age at first-mating [AFM] was examined in gilts, records were omitted if there was no record of $\operatorname{AFM}(7,701$ females) or if the AFM record was either less than 160 days or more than 400 days $(11,885$ females; Hoving et al., 2011). Hence, Dataset 2 comprised 558,486 first-served records in 113,517 females. Dataset 3 comprised the same records as Dataset 2 except for the further removal of records of served females that were removed before farrowing (40,600 served records). Hence, Dataset 3 comprised 517,886 first-served and subsequently farrowed records of 105,198 sows. 


\subsection{Definitions and Categories}

By-parity mortality risks (\%) for pigs served and sows farrowed were defined as the number of deaths divided by the number of female pigs served and sows farrowed, respectively, at that parity $\times 100$. The by-parity mortality incidence rates for (a) pregnant pigs and (b) farrowed sows are defined as follows:

(a) the number of female pigs that died in a given parity divided by the number of days from service to either death or farrowing $\times 100$, and (b) the number of sows that died in a given parity or before the subsequent service divided by the number of days from farrowing to either death or subsequent service $\times 100$.

Two herd groups were defined on the basis of the lower $25^{\text {th }}$ percentiles of the herd means of annualized lifetime pigs weaned per sow: low-performing herds $(<21.2$ pigs $)$ and ordinary herds $(\geq 21.2$ pigs $)$. In preliminary analysis, there were no differences in mortality risks between the upper two of the three herd groups based on the $25^{\text {th }}$ and $75^{\text {th }}$ percentiles of annualized lifetime pigs weaned per sow. The annualized lifetime pigs weaned per sow was defined as the lifetime number of weaned pigs divided by the sum of the reproductive herd life days $\times$ 365 days. Also, a reproductive herd life day was defined as the number of days from the date that the sows were first-mated to their removal (Sasaki \& Koketsu, 2011). Additionally, two groups of WMI were formed: 0 to 6 days and 7 days or higher. Also, three groups of stillborn piglets were formed: 0, 1-2 and 3 piglets or more. Served or farrowed months were categorized into four seasons: January to March (winter), April to June (spring), July to September (summer) and October to December (autumn).

\subsection{Statistical Analysis}

All statistical analyses were carried out using the SAS system version 9.3 (SAS Institute Inc. Cary, NC, U.S.A.). Descriptive statistics and proportions of death interval in different weeks in Dataset 1 were obtained using the FREQ procedure.

A two-level Cox proportional hazards model with the PHREG procedure was performed to compare mortality hazards in a service cycle (from one service to the subsequent service) by herd productivity groups, served months, WMI and the three stillborn piglets groups ( $0,1-2$ and 3 or more piglets), and to estimate survivor functions and probabilities. Also, the COVS $<$ (AGGREGATE) $>$ option in the PHREG procedure was used to make robust variance estimation taking into account the clustering of sows within a herd (Amrhein, 2014). The survival probabilities indicate estimates of the survivor functions (Allison, 1995). Culled and euthanized females in each parity were treated as censored subjects. Also, the censored time in the surviving females was 26 weeks after service. Females were stratified according to parity (gilts, parity 1, 2, 3, 4, 5 and 6) because modelling the baseline hazard function within a parity has been recommended in survival analysis, rather than modelling over the entire life of the animals (Röxström et al., 2003). Herd productivity groups, service months, herd size and entry years were added to all the models. The model for the pregnant gilts included AFM, whereas the models for sows included the three stillborn piglet groups, lactation length and two WMI groups. In these survival analyses, all the models included the herd as a random intercept.

A log-binomial regression model was applied to the binary outcome in Dataset 3, i.e. whether or not a female pig died (1 or 0 ) by using the GLIMMIX procedure with a log link function with binomial distribution (DIST = BIN, LINK $=$ LOG). The ILINK (inverse link function) was used to convert the logarithm to a probability (Littell et al., 2006). Two-level analysis was applied to the models by using a herd as level 2 and an individual record as level 1. All the analyses were performed by parity in order to use the population at risk for farrowed sows at each parity. In Dataset 3, the models for farrowed sows included the four farrowing season groups, the three stillborn piglet groups, the two herd productivity groups, the entry year and herd size. Both the quadratic expressions of continuous variables and possible interactions between two factors were examined, and then non-significant variables, expressions and interactions were eliminated (Wald's test, $P \geq 0.05$ ). Pairwise multiple comparisons were performed using the Tukey-Kramer test. Also, a random herd effect was included in all the models.

\subsection{Intraclass Correlation Coefficient}

To assess the variation in the mortality risks that could be explained by the herd, the intraclass correlation coefficients [ICC] were calculated by the following equation (Equation 1, Dohoo et al., 2009):

$$
\text { ICC (records within the same herd) }=\delta_{v}{ }^{2} /\left[\delta_{v}^{2}+\left(\pi^{2} / 3\right)\right]
$$

Where, $\delta_{v}^{2}$ is the between-herd variance and $\pi^{2} / 3$ is the variance at the assumed individual record level.

\section{Results}

A total of 16,396 (14.4\%) of the females died before they were culled from the studied herds, with a mean parity at death of 3.4, ranging from 0 to 12 . The mean ( \pm SEM) last-service-to-death interval for pregnant pigs was 73.2 
( \pm 0.43 ) days and the farrowing-to-death interval for sows that had farrowed but subsequently died was $20.1( \pm$ 0.16) days (Table 1). The relative frequency (\%) of the number of females that died in the weeks before or after farrowing is shown in Figure 1: $10.4 \%$ were pregnant pigs that died 1 week prior to expected farrowing (due date) or at farrowing, and $38.0 \%$ were farrowed sows that subsequently died between 0 and 4 weeks after farrowing.

Table 1. Reproductive data for breeding-female pigs in 121 commercial breeding herds

\begin{tabular}{|c|c|c|c|c|}
\hline \multirow{2}{*}{ Measurements } & \multirow{2}{*}{$\mathrm{N}$} & \multirow{2}{*}{ Mean \pm SEM } & \multicolumn{2}{|c|}{ Range } \\
\hline & & & Minimum & Maximum \\
\hline \multicolumn{5}{|l|}{ First-served females } \\
\hline Number of parity & 558486 & $2.6 \pm 0.01$ & 0 & 12 \\
\hline Mortality risk per first-service, $\%$ & 558486 & $1.5 \pm 0.01$ & - & - \\
\hline Weaning-to-first-mating interval, days ${ }^{1}$ & 440443 & $5.9 \pm 0.01$ & 0 & 35 \\
\hline Number of stillborn piglets ${ }^{1}$ & 444937 & $0.9 \pm 0.01$ & 0 & 23 \\
\hline Lactation length, days ${ }^{1}$ & 443002 & $23.7 \pm 0.01$ & 0 & 41 \\
\hline \multicolumn{5}{|l|}{ Sows farrowed } \\
\hline Number of parity & 517886 & $2.6 \pm 0.01$ & 0 & 12 \\
\hline Mortality risk for sows farrowed, $\%$ & 517886 & $1.6 \pm 0.01$ & - & - \\
\hline Number of stillborn piglets ${ }^{2}$ & 517852 & $0.9 \pm 0.01$ & 0 & 25 \\
\hline \multicolumn{5}{|l|}{ Lifetime records } \\
\hline Removal parity & 113517 & $4.6 \pm 0.01$ & 0 & 13 \\
\hline Age at first-mating ${ }^{3}$, days old & 106660 & $254.2 \pm 0.13$ & 160 & 400 \\
\hline Parity at death & 16396 & $3.4 \pm 0.02$ & 0 & 12 \\
\hline Last-service-to-death interval for pregnant pigs, days ${ }^{4}$ & 7778 & $73.2 \pm 0.43$ & 0 & 122 \\
\hline Farrow-to-death interval for sows farrowed, days ${ }^{4}$ & 7745 & $20.1 \pm 0.16$ & 0 & 70 \\
\hline \multicolumn{5}{|l|}{ Pig days of female pigs } \\
\hline Service-to-death interval for pregnant pigs, days & 7821 & $77.7 \pm 0.44$ & 0 & 153 \\
\hline Farrow-to-death interval for sows farrowed, days & 7765 & $20.1 \pm 0.17$ & 0 & 70 \\
\hline
\end{tabular}

Note. ${ }^{1}$ The remaining records $(558,486-\mathrm{N})$ were regarded as missing records; ${ }^{2}$ The remaining records $(517,886-\mathrm{N})$ were regarded as missing records; ${ }^{3}$ The remaining records $(113,517-\mathrm{N})$ were regarded as missing records; ${ }^{4}$ The remaining records $(16,396-\mathrm{N})$ were regarded as missing records.

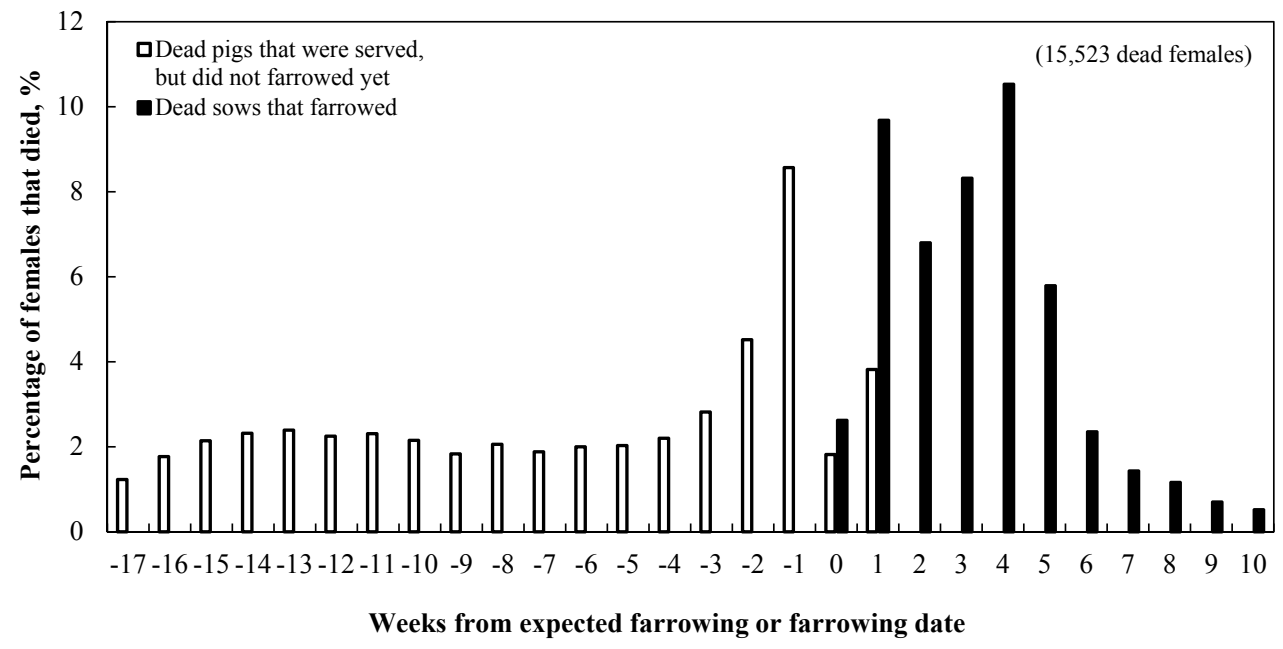

Figure 1. Relative frequencies (\%) of female pig deaths before and after farrowing of 7778 served pigs and 7745 farrowed sows

Note. Week 0 is the farrowing or expected farrowing date.

Records of pregnant females that had a last gestation length of 123 days or more (447 females) were omitted. In addition, records were also omitted for sows that had farrowed and subsequently died on 11 or more weeks after farrowing (426 sows). 
Mean by-parity mortality risks $( \pm \mathrm{SEM})$ for pregnant pigs and farrowed sows were $1.5 \pm 0.01$ and $1.6 \pm 0.01 \%$, respectively (Table 2). Table 2 also shows mortality incidence rates by parity groups. For example, overall means of mortality incidence rates for pregnant female pigs and farrowed sows were 1.22 and 5.30 pigs per 100 pig-days of observation, respectively. The mortality incidence rates in parity 1-7 farrowed sows were 3.3-5.2 times higher than the respective incidence rates for pregnant females (Table 2). The highest risks of pregnant females dying after service were for gilts and parity 4 or higher sows. In contrast, the highest risks of sows dying after farrowing were for parity 1 and parity 6 or higher farrowed sows.

Table 2. By-parity mortality incidence rates (\%) and mortality risks for first-served female pigs

\begin{tabular}{|c|c|c|c|c|c|c|c|c|}
\hline \multirow{2}{*}{ Measurements } & \multicolumn{8}{|c|}{ Served parity } \\
\hline & 0 & 1 & 2 & 3 & 4 & 5 & $6^{1}$ & Total \\
\hline Number of pregnant pigs & 113517 & 98426 & 87449 & 77087 & 66141 & 53688 & 36602 & 558486 \\
\hline Death records before farrowing & 1608 & 1206 & 1118 & 1061 & 1065 & 930 & 675 & 8201 \\
\hline Mortality risks for pregnant pigs, $\%$ & 1.4 & 1.2 & 1.3 & 1.4 & 1.6 & 1.7 & 1.8 & 1.5 \\
\hline Mortality incidence rates for 100 pig-days of observation, pigs $^{3}$ & 1.08 & 0.92 & 0.97 & 1.07 & 1.31 & 1.65 & 2.31 & 1.22 \\
\hline \multirow{2}{*}{ Measurements } & \multicolumn{8}{|c|}{ Farrowed parity } \\
\hline & 1 & 2 & 3 & 4 & 5 & 6 & $7^{1}$ & Total \\
\hline Number of sows farrowed in current parity ${ }^{2}$ & 105198 & 92102 & 82360 & 72040 & 61326 & 49126 & 33008 & 517886 \\
\hline Death records before subsequent service & 1766 & 1053 & 1072 & 964 & 909 & 1089 & 751 & 8195 \\
\hline Mortality risks for farrowed sows, $\%$ & 1.7 & 1.1 & 1.3 & 1.3 & 1.5 & 2.2 & 2.3 & 1.6 \\
\hline Mortality incidence rates for 100 sow-days of observation, pigs $^{3}$ & 5.63 & 3.82 & 4.36 & 4.48 & 4.96 & 7.44 & 7.63 & 5.30 \\
\hline
\end{tabular}

Note. ${ }^{1}$ Ratio of mortality incidence rate and mortality risk of sows in parity 7 or higher are not shown in the Table 2 because these variables values are similar to parity 6 sows; ${ }^{2}$ Number of sows farrowed was calculated as the number of served records subtracted by the number of female pigs that died or were culled before farrowing; ${ }^{3}$ The records of pig days for removed pregnant females with more than 153 days after last service, or pig days for removed females with more than 71 days after farrowing, were regarded as missing records when mortality incidence rates were calculated.

Lower survival probabilities for served females in all parity groups were associated with females being fed in low-performing herds, farrowing more stillborn piglets and having WMI of 7 days or more in any parity $(\mathrm{P}<$ 0.05 ). Survival probabilities in winter served groups in parities 0,1 and 3 were lower than in respective autumn served groups. In addition, lower survival probabilities in served gilts were associated with females having prolonged AFM $(\mathrm{P}<0.05)$. However, neither lactation length nor herd size was associated with survival probabilities for served females in any parity group $(\mathrm{P} \geq 0.14)$. By-parity survival probability curves are shown in Figures 2-6. Survival probabilities decreased by 2.3-3.7\% around farrowing from 15 to 22 weeks of gestation in all parity groups (Figure 2). 


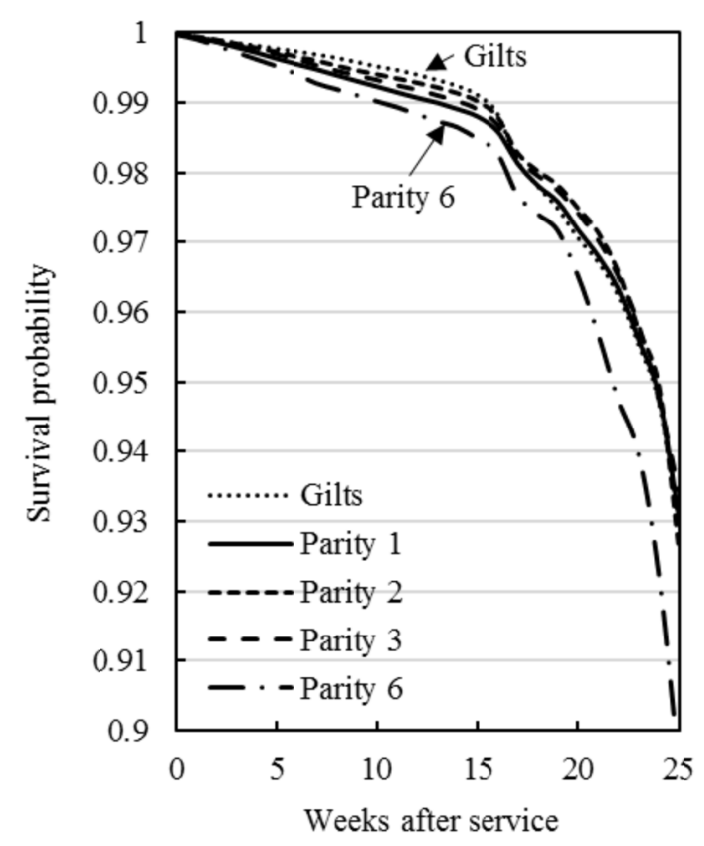

Figure 2. By-parity survival curves of served female pigs from the date of service until death

Note. Parities 4 and 5 are not shown in the figure because the probability curves are between those of parity 3 and parity 6 sows.

However, there was a difference in the changes over time in survival probabilities between the herd productivity groups (Figure 3). The survival probabilities for pregnant pigs in low-performing herds decreased more rapidly from 15 weeks after service than those in ordinary herds. Also, the survival probability for sows was affected by WMI, with a more rapid decrease in survival probability from 15 weeks after service for sows with WMI of 7 days or more than there was for sows with WMI of 0-6 days (Figure 4). A similar effect was found for sows with different numbers of stillborn piglets (Figure 5). The survival probability for sows that had farrowed 3 or more stillborn piglets decreased more rapidly around the time of the next farrowing than it did for sows with 0 stillborn piglets. Lastly, it was also found that AFM in gilts affected survival probability from 15 weeks after service, with a more rapid decrease in survival probability for gilts with AFM of more than 226 days than for gilts with AFM of less than 227 days (Figure 6). For example, between 15 to 22 weeks of gestation the survival probabilities for pigs farrowing either 3 or more stillborn piglets, or having WMI of 7 days or more, or being fed in low-performing herds were up to $1.3 \%$ lower than for pigs farrowing 0 stillborn piglets, WMI $0-6$ or being in ordinary herds, respectively. In addition, over the same time period survival probabilities for served female pigs first-mated at 277-400 days of age were up to 1.1\% lower than those first-mated at 160-227 days of age. 

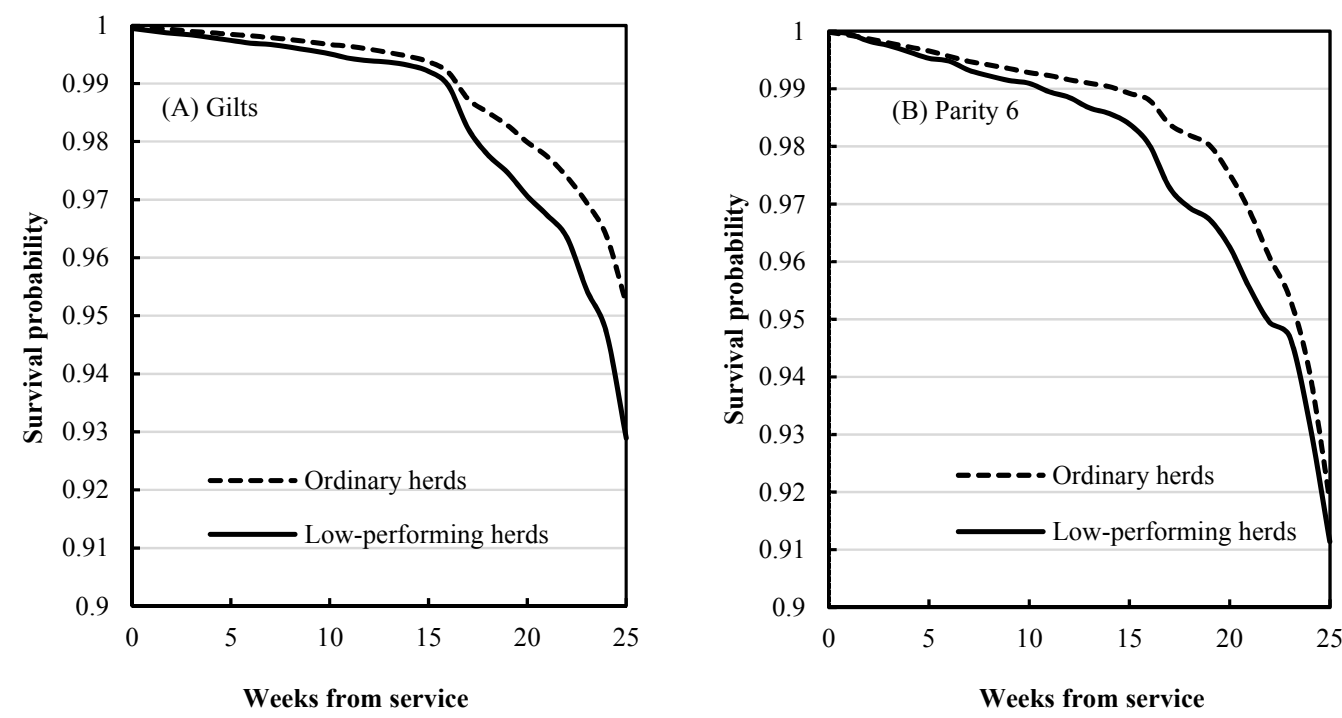

Figure 3. Survival probability curves from date of service until death for (A) served gilts and (B) served sows in parity 6 in both low-performing and ordinary herds

Note. Parities 1-5 are not shown in the figure because the probability curves are very similar to those for the gilts or parity 6 sows.
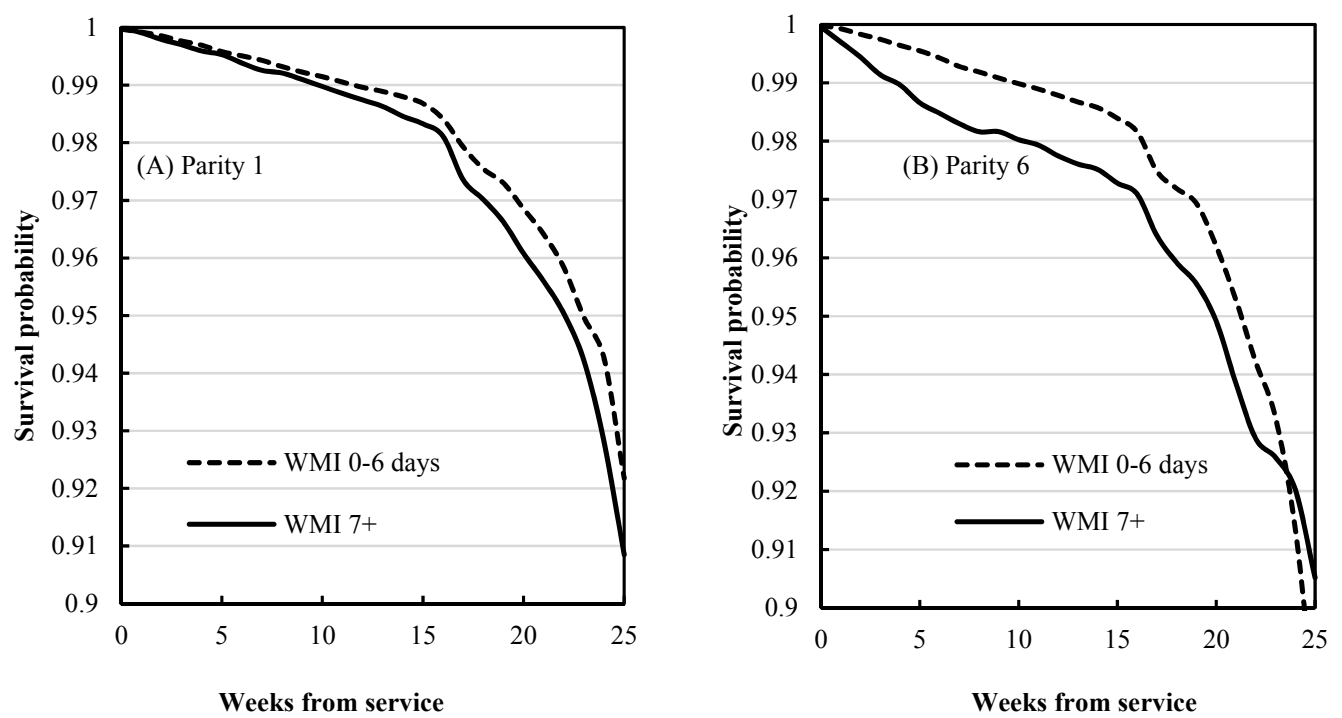

Figure 4. Survival probability curves from date of service until death for (A) parity 1 sows and (B) parity 6 sows in the two weaning-to-first-mating interval (WMI) groups

Note. Parities 2-5 are not shown in the figure because the probability curves are very similar to those for sows in parities 1 or 6 . 

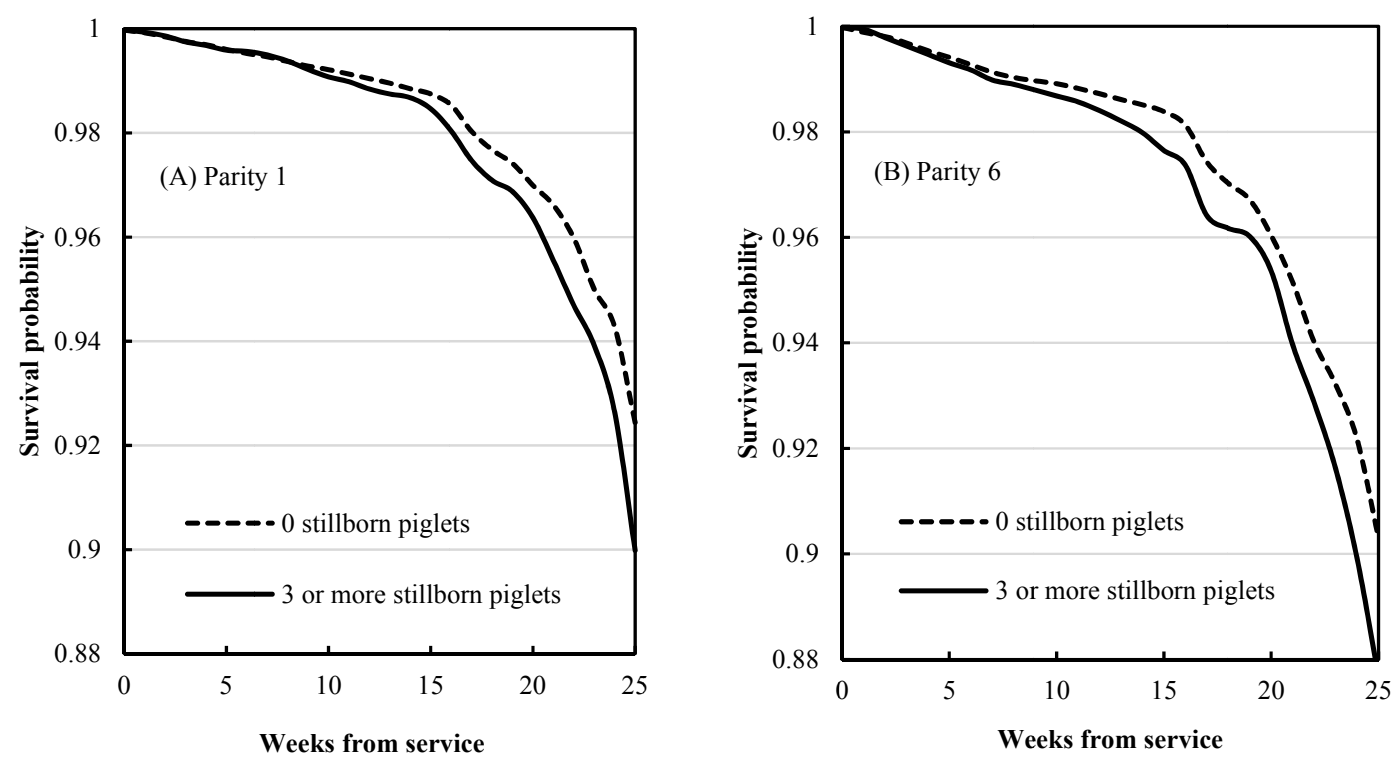

Figure 5. Survival probability curves from date of service until death for (A) parity 1 sows and (B) parity 6 sows in two stillborn piglet groups

Note. Parities 2-5 are not shown in the figure because the probability curves are very similar to those for sows in parities 1 or 6 . Probability curves for females with 1-2 stillborn piglets were not shown because the line falls between those for 0 and 3 or more stillborn piglets.

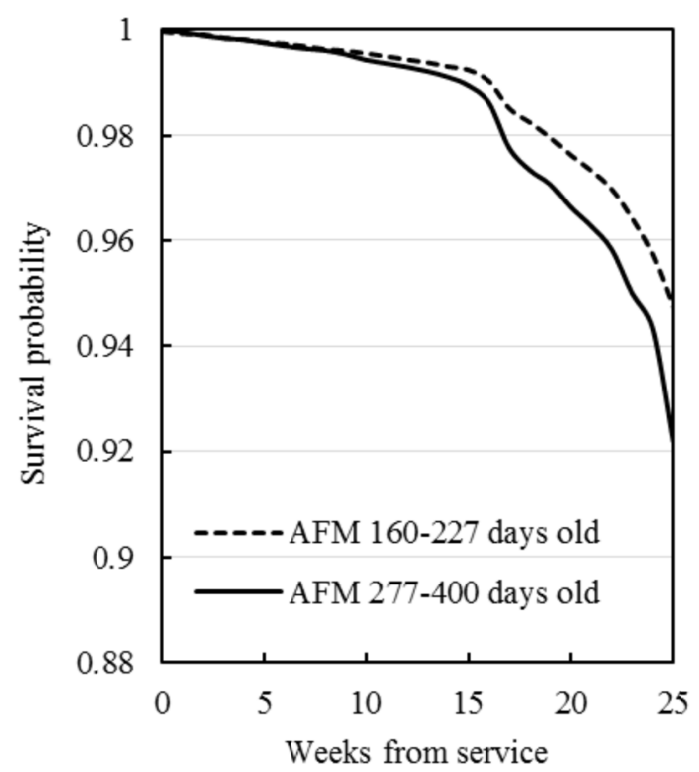

Figure 6. Survival probability curves from date of service until death for served gilts that were either less than 228 days old or and more than 276 days old at first-mating (AFM)

For farrowed sows, an increased number of stillborn piglets was associated with increased by-parity mortality risks in all parity groups $(\mathrm{P}<0.05$; Table 3$)$. Increased mortality risks were also associated with parities 1-5. Additionally, farrowing in summer was associated with an increased mortality risk in parities 1-4, while farrowing in spring was associated with increased mortality risk in parity 6. For example, mortality risks for parity 1-5 farrowed sows being fed in low-performing herds were $0.5-1.0 \%$ higher than those for equivalent sows in ordinary herds (Table 4; $\mathrm{P}<0.05$ ). Mortality risks for parity 1-6 sows farrowing 3 or more stillborn piglets were 1.3-2.2\% higher than those for the same parity sows with 0 stillborn piglets (Table $4 ; \mathrm{P}<0.05$ ). Also, 
mortality risks for parity $1-4$ sows that farrowed in summer were $0.7-0.8 \%$ higher than the same parity sows farrowing in autumn (Table 4; $\mathrm{P}<0.05$ ). However, herd size was not associated with farrowed sow mortality risk in any parity group $(\mathrm{P} \geq 0.05)$. Meanwhile, low-performing herds had smaller herd size than ordinary herds (479 v.s. 745, respectively; $\mathrm{P}<0.05$ ). Additionally, there was no two-way interaction between any of the above mentioned factors for mortality risks $(\mathrm{P} \geq 0.05)$. With regard to the ICC, the random herd effect explained $5.9 \%-9.5 \%$ of total variance in mortality risks for sow models (Table 3 ).

Table 3. Estimates of factors in the final log-binomial regression models for mortality risks of farrowed sows

\begin{tabular}{|c|c|c|c|}
\hline \multirow{2}{*}{ Fixed and random effects ${ }^{1}$} & Parity 1 & Parity 2 & Parity 3 \\
\hline & Estimate $( \pm \mathrm{SE})$ & Estimate $( \pm \mathrm{SE})$ & Estimate $( \pm \mathrm{SE})$ \\
\hline Intercept & $-4.513(0.089)^{1}$ & $-4.960(0.113)^{1}$ & $-4.914(0.110)^{1}$ \\
\hline \multicolumn{4}{|l|}{ Farrowed season } \\
\hline Jan.-Mar. & $-0.049(0.073)$ & $0.200(0.098)$ & $0.259(0.094)^{2}$ \\
\hline Apr.-Jun. & $0.212(0.070)^{2}$ & $0.329(0.097)^{2}$ & $0.090(0.098)$ \\
\hline Jul.-Sep. & $0.330(0.067)^{2}$ & $0.542(0.092)^{2}$ & $0.431(0.090)^{2}$ \\
\hline Low-performing herds & $0.438(0.124)^{3}$ & $0.471(0.143)^{3}$ & $0.410(0.129)^{3}$ \\
\hline \multicolumn{4}{|l|}{ Stillborn piglets } \\
\hline 1-2 piglets & $0.206(0.054)^{4}$ & $0.061(0.077)$ & $0.237(0.070)^{4}$ \\
\hline 3 piglets or more & $0.935(0.066)^{4}$ & $0.899(0.095)^{4}$ & $0.957(0.086)^{4}$ \\
\hline Herd variance & $0.2(0.05)$ & $0.3(0.06)$ & $0.2(0.04)$ \\
\hline ICC (records within the same herd) & 6.8 & 7.9 & 5.9 \\
\hline \multirow{2}{*}{ Fixed and random effects ${ }^{1}$} & Parity 4 & Parity 5 & Parity 6 \\
\hline & Estimate $( \pm \mathrm{SE})$ & Estimate $( \pm \mathrm{SE})$ & Estimate $( \pm \mathrm{SE})$ \\
\hline Intercept & $-4.688(0.110)^{1}$ & $-4.156(0.110)^{1}$ & $-4.275(0.115)^{1}$ \\
\hline \multicolumn{4}{|l|}{ Farrowed season } \\
\hline Jan.-Mar. & $0.173(0.099)$ & $0.050(0.095)$ & $0.321(0.093)^{2}$ \\
\hline Apr.-Jun. & $0.394(0.095)^{2}$ & $0.057(0.095)$ & $0.555(0.087)^{2}$ \\
\hline Jul.-Sep. & $0.441(0.093)^{2}$ & $0.069(0.097)$ & $0.251(0.091)^{2}$ \\
\hline Low-performing herds & $0.329(0.082)^{3}$ & $0.387(0.139)^{3}$ & $0.105(0.160)$ \\
\hline \multicolumn{4}{|l|}{ Stillborn piglets } \\
\hline $1-2$ pigs & $0.116(0.074)^{4}$ & $-0.013(0.075)$ & $0.001(0.071)$ \\
\hline 3 piglets or more & $0.773(0.087)^{4}$ & $0.417(0.091)^{4}$ & $0.573(0.077)^{4}$ \\
\hline Herd variance & $0.2(0.05)$ & $0.2(0.05)$ & $0.3(0.07)$ \\
\hline ICC (records within the same herd) & 6.7 & 6.7 & 9.5 \\
\hline
\end{tabular}

Note. 1SE: standard error; ICC: intraclass correlation coefficient.

${ }^{1}$ indicates significant difference at the $\mathrm{P}<0.05$ level compared to $0 ;{ }^{2-4}$ indicates significant difference at the $\mathrm{P}<$ 0.05 level compared to the appropriate reference value (Oct.-Dec. ${ }^{2}$, ordinary herds ${ }^{3}$ and 0 stillborn piglets $^{4}$ ).

The relative risk ratios of parity 1-4 summer farrowed sows dying were 1.39-1.72, compared to the same parity sows that farrowed in autumn (Table 4). Also, the relative risk ratios of spring farrowed parity 6 sows dying was 1.74 , compared to parity 6 sows farrowed in autumn. The relative risk ratios of dying also differed between herd groups, with parity 1-5 farrowed sows that were fed in low-performing herds having risk ratios of 1.38-1.60, compared to the same parity sows being fed in ordinary herds. Lastly, the relative risk ratios of dying for sows that had farrowed 3 or more stillborn piglets were 1.52-2.60, compared to sows that had not farrowed any stillborn piglets (Table 4). 
Table 4. Comparisons of mortality risks (\%) and relative risk ratios of different parity sows, estimated by the model for farrowed sows

\begin{tabular}{|c|c|c|c|c|c|c|}
\hline \multirow{2}{*}{ Groups } & Parity 1 & Parity 2 & Parity 3 & Parity 4 & Parity 5 & Parity 6 \\
\hline & \multicolumn{6}{|c|}{ Mortality risks $( \pm \mathrm{SE})$} \\
\hline \multicolumn{7}{|l|}{ Farrowed season } \\
\hline Jan.-Mar. & $1.9(0.2) \mathrm{c}$ & $1.3(0.1) b c$ & $1.7(0.1) \mathrm{ab}$ & $1.5(0.1) b c$ & $1.7(0.2)$ & $2.1(0.2) \mathrm{b}$ \\
\hline Apr.-Jun. & $2.3(0.2) \mathrm{b}$ & $1.5(0.1) \mathrm{ab}$ & $1.4(0.1) b c$ & $1.8(0.2) \mathrm{ab}$ & $1.7(0.2)$ & $2.6(0.2) \mathrm{a}$ \\
\hline Jul.-Sep. & $2.6(0.2) \mathrm{a}$ & $1.9(0.2) \mathrm{a}$ & $2.0(0.2) \mathrm{a}$ & $1.9(0.2) \mathrm{a}$ & $1.7(0.2)$ & $1.9(0.2) \mathrm{b}$ \\
\hline Oct.-Dec. & $1.8(0.1) \mathrm{c}$ & $1.1(0.1) \mathrm{c}$ & $1.3(0.1) \mathrm{c}$ & $1.2(0.1) \mathrm{c}$ & $1.6(0.2)$ & $1.5(0.2) \mathrm{c}$ \\
\hline \multicolumn{7}{|l|}{ Herd groups } \\
\hline LP herds & $2.7(0.3) \mathrm{a}$ & $1.8(0.2) \mathrm{a}$ & $2.0(0.2) \mathrm{a}$ & $1.9(0.2) \mathrm{a}$ & $2.1(0.3) \mathrm{a}$ & $2.1(0.3)$ \\
\hline OP herds & $1.7(0.1) \mathrm{b}$ & $1.1(0.1) b$ & $1.3(0.1) \mathrm{b}$ & $1.4(0.1) \mathrm{b}$ & $1.4(0.1) b$ & $1.9(0.1)$ \\
\hline \multicolumn{7}{|l|}{ Stillborn piglets } \\
\hline 0 piglets & $1.5(0.1) \mathrm{c}$ & $1.0(0.1) \mathrm{b}$ & $1.1(0.1) \mathrm{c}$ & $1.2(0.1) \mathrm{b}$ & $1.5(0.1) \mathrm{b}$ & $1.6(0.1) \mathrm{b}$ \\
\hline 1-2 piglets & $1.8(0.1) \mathrm{b}$ & $1.1(0.1) b$ & $1.4(0.1) b$ & $1.3(0.1) \mathrm{b}$ & $1.5(0.1) \mathrm{b}$ & $1.6(0.1) \mathrm{b}$ \\
\hline 3 piglets or more & $3.7(0.3) \mathrm{a}$ & $2.5(0.3) \mathrm{a}$ & $2.8(0.3) \mathrm{a}$ & $2.6(0.2) \mathrm{a}$ & $2.3(0.2) \mathrm{a}$ & $2.9(0.3) \mathrm{a}$ \\
\hline Groups & \multicolumn{6}{|c|}{ Relative risk ratio $(95 \% \mathrm{CI})$} \\
\hline \multicolumn{7}{|l|}{ Farrowed season } \\
\hline Jan.-Mar. & $1.1(0.91-1.21)$ & $1.2(1.01-1.48)$ & $1.3(1.08-1.56)$ & $1.2(0.98-1.44)$ & $1.1(0.87-1.27)$ & $1.4(1.15-1.65)$ \\
\hline Apr.-Jun. & $1.2(1.08-1.42)$ & $1.4(1.15-1.68)$ & $1.1(0.90-1.32)$ & $1.5(1.23-1.79)$ & $1.1(0.88-1.27)$ & $1.7(1.47-2.07)$ \\
\hline Jul.-Sep. & $1.4(1.22-1.59)$ & $1.7(1.44-2.06)$ & $1.5(1.29-1.83)$ & $1.6(1.30-1.87)$ & $1.1(0.89-1.29)$ & $1.3(1.07-1.54)$ \\
\hline Oct.-Dec. & Reference & Reference & Reference & Reference & Reference & Reference \\
\hline \multicolumn{7}{|l|}{ Herd groups } \\
\hline LP herds & $1.6(1.22-1.97)$ & $1.6(1.21-2.12)$ & $1.5(1.17-1.94)$ & $1.4(1.05-1.80)$ & $1.5(1.12-1.93)$ & $1.1(0.81-1.52)$ \\
\hline OP herds & Reference & Reference & Reference & Reference & Reference & Reference \\
\hline \multicolumn{7}{|l|}{ Stillborn piglets } \\
\hline 0 piglets & Reference & Reference & Reference & Reference & Reference & Reference \\
\hline $1-2$ piglets & $1.2(1.11-1.37)$ & $1.1(0.92-1.22)$ & $1.3(1.11-1.45)$ & $1.1(0.97-1.30)$ & $1.0(0.85-1.14)$ & $1.0(0.87-1.15)$ \\
\hline 3 piglets or more & $2.6(2.24-2.90)$ & $2.5(2.04-2.96)$ & $2.6(2.20-3.08)$ & $2.2(1.83-2.57)$ & $1.5(1.27-1.81)$ & $1.8(1.52-2.06)$ \\
\hline
\end{tabular}

Note. SE: standard error; LP: Low-performing herds; OP: Ordinary herds

${ }^{a-c}$ Mean values within a column followed by different letters differ $(\mathrm{P}<0.05)$. The comparisons at each parity were between either farrowed season groups, herd productivity groups or stillborn piglet groups.

\section{Discussion}

Our study clearly shows that the peripartum period is a critical time for pigs' survival. These deaths with the rapidly decreased survival probabilities from week 15 of gestation in all the parity groups indicate that late gestation is another important risk period for female deaths. Our study data are consistent with previous reports in Canada and Japan showing major risks of sows dying around farrowing (Chagnon et al., 1991; Sasaki \& Koketsu, 2007). Therefore, these data show that it is important to individually monitor pregnant females in late gestation. Some of the possible causes of such deaths in female pigs are heart failure, distortions of abdominal organs, cystitis or pyelonephritis and uterine prolapse (Stalder et al., 2012). Also, some pathways are possibly associated with postpartum dysgalactia syndrome (Martineau et al., 2012).

The two highest post farrowing mortality incidence rates were in parity 6-7 sows, which indicates that aged sows are at the highest risk of dying after farrowing. Our study also showed that the reduction in survival probability from 15 weeks after service was greater in parity 6 sows than in parity 2 sows. One possible reason for these lower survival probabilities in aged sows is due to physiological stress after farrowing, as a result of delayed recovery due to a slower response of reproductive organs to a farrowing event. More stillborn piglets and prolonged WMI also resulted in reduced survival probabilities after service. Both of these situations were more common in aged sows, with some aged sows that had farrowed more stillborn piglets have delayed uterine recovery, reduced feed intake, delayed post weaning estrus and thus prolonged WMI. 
Also, the first experience of farrowing in parity 1 sows appeared to increase mortality risk in the studied herds. Pregnant gilts are still growing and their bodies have not yet matured (Rozeboon et al., 1996), and so their small pelvis may increase difficulty in farrowing. This difficulty could be increased further by using of semen of big sires to mate young females for the first time. Our study also showed a slightly lower survival probability associated with higher AFM which suggests that some high aged pregnant gilts are at risk of dying around farrowing. One possible reason for these lower survival probabilities in gilts having high AFM is that heat stressed gilts have delayed puberty (D'Allaire et al., 1996) and that some of these gilts with poor body conditions are likely to die earlier (Tina et al., 2012).

The relative risk ratios calculated in our study indicate that sows farrowed in summer were 1.4-1.7 times more likely to die compared to those farrowed in autumn. A possible reason for the higher summer deaths is that pigs are susceptible to heat stress because they have a weak cardiovascular system and limited ability to sweat (Fraser, 1970). However, in an earlier study we found that high outdoor temperature in the week prior to the due date was only associated with a higher mortality in parity 0-1 females (Iida \& Koketsu, 2014). The discrepancy between these two studies could be explained by the fact that the Iida and Koketsu (2014) study only focused on the last week before the due date. The result from the current study showing higher mortality risks for summer farrowing compared to farrowing in other seasons is consistent with previous reports in the U.S.A. and Japan (Koketsu, 2000; Iida \& Koketsu, 2014). In contrast, the lower mortality risks for females served in summer, compared to those served in other seasons, appears to be due to the lack of any exposure to heat stress in the peripartum period decreasing the risk of summer served sows dying.

A new finding from the current study is that gilts and sows being fed in low-performing herds have lower survival probabilities, and are 1.4-1.6 times more likely to die than those in ordinary herds. This finding suggests that herd health, care management or production systems in low-performing herds are not good enough to reduce mortality in females at risk. For example, workers in low-performing herds are less likely to recognize a female at risk and intervene with a treatment or make a decision to cull the sows promptly (Loula, 2000). Also, greater mortality increases non-productive days and decreases both numbers of pigs born alive and herd productivity, and so herds with high mortality will become low-performing herds.

In addition, our study indicates that more stillborn piglets will increase the mortality risk in commercial herds. The association between the number of stillborn piglets and sows' mortality can be explained by the increased likelihood of an infection event around farrowing or retained placenta (Almond et al., 2006), as well as manual interventions for difficult farrowing. Finally, the ICC for herd variance was 5.9-9.5\%, which is relatively high indicating that there were some effects of the herd on death occurrences, such as management or production system.

The lack of any association between herd size and death occurrence in our data is in agreement with other Danish and Japanese studies (Jensen et al., 2012; Iida \& Koketsu, 2014). Any herd size effects could be partly explained by the low-performing and ordinary herd effects found in our analysis. For example, large sized ordinary herds tend to hire more skilled workers and use better facilities than small low-performing herds (King et al., 1998). In conclusion, in order to prevent female pig death occurrences, producers need to individually monitor females at high risk of dying, and provide prompt treatment to females having a problem. The females at high risk of dying included females in peripartum periods, high parity sows, sows farrowing more stillborn piglets, sows farrowing in summer and those being fed in low-performing herds.

Finally, there are some limitations that should be noted when interpreting the results of this observational study using commercial herd data. Our studied herds were not randomly collected in two countries. Our analyses did not take account of health status, nutritional programs, genotype, ventilation type or sire effects. However, even with such limitations, this research provides valuable information about the quantitative relationship between production factors and mortality risks for swine producers and veterinarians.

\section{References}

Allison, P. D. (1995). Survival Analysis Using SAS®: A Practical Guide. SAS Inst. Inc., Cary, NC.

Almond, G. W., Flowers, W. L., Batista, L., \& D'Allaire, S. (2006). Diseases of the reproductive system. In B. E. Straw, J. J. Zimmerman, S. D’Allaire, \& D. J. Taylor (Eds.), Diseases of Swine (9th ed., pp. 113-147). Blackwell publishing, Ames, IA, USA.

Amrhein, J. (2014). Introduction to Frailty Models. Retrieved November, 2016 from http://support.sas.com/ resources/papers/proceedings14/1492-2014.pdf 
D’Allaire, S., Drolet, R., \& Brodeur, D. (1996). Sow mortality associated with high ambient temperatures. The Canadian Veterinary Journal, 37, 237-239.

Dohoo, I. R., Martin, S. W., \& Stryhn, H. (2009). Veterinary Epidemiologic Research (2nd ed.). VER Inc. Charlottetown, Prince Edwards Island, Canada.

European Commission. (2016). Pig: Number of farms and heads by agricultural size of farm (UAA) and size of pig herd. Retrieved December, 2016, from http://appsso.eurostat.ec.europa.eu/nui/submitViewTable Action.do

Fraser, A. F. (1970). Studies on heat stress in pigs in a tropical environment. Tropical Animal Health and Production, 2, 76-86. https://doi.org/10.1007/BF02359573

Hoving, L., Soede, N., Graat, E., Feitsma, H., \& Kemp, B. (2011). Reproductive performance of second parity sows: Relations with subsequent reproduction. Livestock Science, 140, 124-130. https://doi.org/10.1016/ j.livsci2011.02019

Iida, R., \& Koketsu, Y. (2014). Climatic factors associated with peripartum pig deaths during hot and humid or cold seasons. Preventive Veterinary Medicine, 115, 166-172. https://doi.org/10.1016/j.prevetmed. 2014.03.019

Iida, R., \& Koketsu, Y. (2015). Climatic factors associated with abortion occurrences in Japanese commercial pig herds. Animal Reproduction Science, 157, 78-86. https://doi.org/10.1016/j.anireprosci.2015.03.018

Jensen, T. B., Toft, N., Bonde, M. K., Kongsted, A. G., Kristensen, A. R., \& Sørensen, J. T. (2012). Herd and sow-related risk factors for mortality in sows in group-housed systems. Preventive Veterinary Medicine, 103 , 31-37. https://doi.org/10.1016/j.prevetmed.2011.09.009

King, V. L., Koketsu, Y., Reeves, D., Xue, J. L., \& Dial, G. D. (1998). Management factors associated with swine breeding herd productivity in the USA. Preventive Veterinary Medicine, 35, $255-264$. https://doi.org/10.1016/S0167-5877(98)00068-3

Koketsu, Y. (2000). Retrospective analysis of trends and production factors associated with sow mortality on swine-breeding farms in USA. Preventive Veterinary Medicine, 46, 249-256. https://doi.org/10.1016/S01675877(00)00153-7

Littell, R. C., Milliken, G. A., Stroup, W. W., Wolfinger, R. D., \& Schabenberger, O. (2006). SAS for Mixed Models (2nd ed.). SAS Institute Inc. Cary, NC, USA.

Loula, T. J. (2000). Increasing sow longevity: The role of people and management. Proc. A. D. Leman Swine Conf., 27, 139-142. Retrieved November 7, 2016, from http://www1.agric.gov.ab.ca/\$department/ newslett.nsf/pdf/bb465/\$file/0010.pdf

Lundgren, H., Canario, L., Grandinson, K., Lundeheim, N., Zumbach, B., Vangen, O., \& Rydhmer, L. (2010). Genetic analysis of reproductive performance in Landrace sows and its correlation to piglet growth. Livestock Science, 128, 173-178. https://doi.org/10.1016/j.livsci.2009.12.002

Martineau, G. P., Farmer, C., \& Peltoniemi, O. (2012). Mammary system. In J. J. Zimmerman, L. A. Karriker, A. Ramirez, K. J. Schwartz, \& G. W. Stevenson (Eds.), Diseases of Swine (10th ed., pp. 270-93). John Wiley \& Sons, Chichester.

PigCHAMP. (2015). PigCHAMP benchmarking. Retrieved November, 2016, from http://www.pigchamp.com/ benchmarking/benchmarking-summaries

Röxström, A., Ducrocq, V., \& Strandberg, E. (2003). Survival analysis of longevity in dairy cattle on a selection basis. Genetics Selection Evolution, 35, 305-318. https://doi.org/10.1186/1297-9686-35-3-305

Rozeboom, D. W., Pettigrew, J. E., Moser, R. L., Cornelius, S. G., \& Kandelgy, S. M. (1996). Influence of gilt age and body composition at first breeding on sow reproductive performance and longevity. Journal of Animal Sciece, 74, 138-150. https://doi.org/10.2527/1996.741138x

Sasaki, Y., \& Koketsu, Y. (2007). Variability and repeatability in gestation length related to litter performance in female pigs on commercial farms. Theriogenology, 68, 123-127. https://doi.org/10.1016/j.theriogenology. 2007.04.021

Sasaki, Y., \& Koketsu, Y. (2008). Mortality, death interval, survivals, and herd factors for death in gilts and sows in commercial breeding herds. Journal of Animal Science, 86, 3159-3165. https://doi.org/10.2527/ jas.2008-1047 
Sasaki, Y., \& Koketsu, Y. (2011). Reproductive profile and lifetime efficiency of female pigs by culling reason in high-performing commercial breeding herds. Journal of Swine Health and Production, 19, 284-291.

Singer, J. D. (1998). Using SAS PROC MIXED to fit multilevel models, hierarchical models, and individual growth models. Journal of Educational and Behavioral Statistics, 23, 323-355. https://doi.org/10.3102/ 10769986023004323

Spiegelman, D., \& Hertzmark, E. (2005). Easy SAS calculations for risk or prevalence ratios and differences. American Journal of Epidemiology, 162, 199-200. https://doi.org/10.1093/aje/kwi188

Stalder, K., D’Allaire, S., Richard, D., \& Abell, C. (2012). Longevity in Breeding Animals. Sow longevity. In J. J. Zimmerman, L. A. Karriker, A. Ramirez, K. J. Schwartz, \& G. W. Stevenson (Eds.), Diseases of Swine (10th ed., pp. 50-59). Blackwell publishing, Ames, IA, USA.

Tani, S., Piñeiro, C., \& Koketsu, Y. (2016). Recurrence patterns and factors associated with regular, irregular, and late return to service of female pigs and their lifetime performance on southern European farms. Journal of Animal Science, 94, 1924-1932. https://doi.org/10.2527/jas2016-0302

Tina, B. J., Nils, T., Marianne, K. B., Anne, G. K., Anders, R. K., \& Jan, T. S. (2012). Herd and sow-related risk factors for mortality in sows in group-housed systems. Preventive Veterinary Medicine, 103, 31-37. https://doi.org/10.1016/j.prevetmed.2011.09.009

Tummaruk, P., Lundeheim, N., Einarsson, S., \& Dalin, A.-M. (2001). Effect of birth litter size, birth parity number, growth rate, backfat thickness and age at first mating of gilts on their reproductive performance as sows. Animal Reproduction Science, 66, 225-237. https://doi.org/10.1016/S0378-4320(01)00095-1

\section{Copyrights}

Copyright for this article is retained by the author(s), with first publication rights granted to the journal.

This is an open-access article distributed under the terms and conditions of the Creative Commons Attribution license (http://creativecommons.org/licenses/by/4.0/). 